\title{
Association of Social Determinants of Health and Their Cumulative Impact on Hospitalization Among a National Sample of Community-Dwelling US Adults
}

\author{
Charlie M. Wray, DO, MS ${ }^{1,2}$ (D), Janet Tang, PhD, MPH' , Lenny López, MD, MPH, MDiv ${ }^{1,2}$, \\ Katherine Hoggatt, $P h D^{1,3}$, and Salomeh Keyhani, MD, MPH ${ }^{1,3}$
}

'Department of Medicine, University of California, San Francisco, San Francisco, USA; ${ }^{2}$ Section of Hospital Medicine, San Francisco Veterans Affairs
Medical Center, San Francisco, USA. ${ }^{3}$ Section of General Internal Medicine, San Francisco Veterans Affairs Medical Center, San Francisco, USA.

IMPORTANCE: While the association between Social Determinants of Health (SDOH) and health outcomes is well known, few studies have explored the impact of SDOH on hospitalization.

OBJECTIVE: Examine the independent association and cumulative effect of six SDOH domains on hospitalization. DESIGN: Using cross-sectional data from the 2016-2018 National Health Interview Surveys (NHIS), we used multivariable logistical regression models controlling for sociodemographics and comorbid conditions to assess the association of each $\mathrm{SDOH}$ and SDOH burden (i.e., cumulative number of SDOH) with hospitalization.

SETTING: National survey of community-dwelling individuals in the US

PARTICIPANTS: Adults $\geq 18$ years who responded to the NHIS survey

EXPOSURE: Six SDOH domains (economic instability, lack of community, educational deficits, food insecurity, social isolation, and inadequate access to medical care)

MEASURES: Hospitalization within 1 year

RESULTS: Among all 55,186 respondents, most were $\leq 50$ years old $(54.2 \%)$, female $(51.7 \%$, 95\% CI $51.1-$ 52.3), non-Hispanic (83.9\%, 95\% CI 82.4-84.5), identified as White $(77.9 \%, 95 \%$ CI 76.8-79.1), and had health insurance (90\%, 95\% CI 88.9-91.9). Hospitalized individuals $(n=5506 ; 8.7 \%$ ) were more likely to be $\geq 50$ years old (61.2\%), female (60.7\%, 95\% CI 58.9-62.4), non-Hispanic (87\%, 95\% CI 86.2-88.4), and identify as White $(78.5 \%$, 95\% CI 76.7-80.3), compared to those who were not hospitalized. Hospitalized individuals described poorer overall health, reporting higher incidence of having $\geq 5$ comorbid conditions (38.9\%, 95\% CI 37.1-40.1) compared to those who did not report a hospitalization (15.9\%, 95\% CI 15.4-16.5). Hospitalized respondents reported higher rates of economic instability (33\%), lack of community (14\%), educational deficits (67\%), food insecurity (14\%), social isolation (34\%), and less access to health care $(6 \%)$ compared to non-hospitalized individuals. In adjusted analysis, food insecurity (OR: 1.36, 95\% CI 1.22-1.52), social isolation (OR: 1.17, 95\% CI 1.08-1.26), and lower educational attainment (OR: 1.12, 95\% CI 1.02-1.25) were associated with hospitalization, while a higher SDOH burden was associated with increased odds of hospitalization (3-4 SDOH [OR: 1.25, 95\% CI 1.06-1.49] and

Received March 26, 2021

Accepted July 21, 2021

Published online August 5, 2021 $\geq 5$ SDOH [OR: $1.72,95 \%$ CI 1.40-2.06]) compared to those who reported no $\mathrm{SDOH}$.

CONCLUSIONS: Among community-dwelling US adults, three SDOH domains: food insecurity, social isolation, and low educational attainment increase an individual's risk of hospitalization. Additionally, risk of hospitalization increases as $\mathrm{SDOH}$ burden increases.

KEY WORDS: social determinants of health; hospitalization.

J Gen Intern Med 37(8):1935-42

DOI: $10.1007 / \mathrm{s} 11606-021-07067-y$

(C) This is a U.S. government work and not under copyright protection in the U.S.; foreign copyright protection may apply 2021

\section{INTRODUCTION}

Hospitalization is a costly resource that accounts for one-third of health care expenditures in the United States (US). ${ }^{1}$ In recent years, health care institutions have placed a larger focus on hospitalization rates in response to financial penalties levied by Medicare's Hospital Readmissions Reduction Program. ${ }^{2}$ While a variety of clinical and epidemiologic factors impact this outcome, a growing body of evidence suggests that individual's social determinants of health $(\mathrm{SDOH})$ - defined by the World Health Organization as the "circumstances in which people are born, grow, work, live, and age and the systems put in place to deal with illness"-also play a significant role. . $^{3-8}$

While previous work has explored the various associations between $\mathrm{SDOH}$ and hospital utilization, gaps in our understanding still exist. First, SDOH assessments are often nonspecific and lack granularity. For instance, many assessments only examine general traits and characteristics (i.e., age, ethnicity, and insurance payor status) that are extractable through administrative or clinical data. ${ }^{3,6,8}$ Such approaches frequently lack individual-level assessments (i.e., food insecurity, social isolation, educational background, and economic stability), which could provide a more granular understanding of an individual's social risk. While general sociodemographic characteristics are helpful, their lack of specificity can lead to non-specific and nonactionable findings - thus hindering improvement efforts by health care systems and policy 
interventions. Second, previous studies of SDOH and hospitalization seldomly account for the simultaneous or cumulative effects of these risk factors. For instance, Johnston et al. recently explored the association of several social risk factors with preventable hospitalizations but did not examine the combinatorial impact of these SDOH on hospitalization. Although previous assessments have examined the incremental impact of SDOH on a variety of other clinical outcomes (e.g., diabetes, stroke risk, heart failure mortality), ${ }^{9-12}$ to our knowledge no previous work has explored the cumulative impact of multiple SDOH on hospitalizations. Given the interconnectedness of these risk factors, assessing the impact of these vulnerabilities in aggregate, rather than individually, would be a more representative assessment of their influence on hospitalization.

To explore this issue, we used the National Health Interview Survey (NHIS), ${ }^{13}$ one of the largest national surveys of community-dwelling Americans, to identify and categorize six individual-level SDOH domains to assess (a) each domains' independent association with hospitalization after accounting for demographics and health status, and (b) the association of SDOH burden with hospitalization. We hypothesized that each individual SDOH would be independently associated with hospitalization and that individuals with a greater $\mathrm{SDOH}$ burden would be at higher risk for hospitalization.

\section{METHODS}

Data Source. We used cross-sectional data from the 20162018 National Health Interview Surveys (NHIS), a national sample of noninstitutionalized individuals residing within the US, conducted annually by the National Center for Health Statistics at the Centers for Disease Control and Prevention. ${ }^{13}$ The NHIS uses computer-assisted personal interviewing to annually administer the survey and collect health-related information from respondents. During the assessed years, the unconditional final sample adult response rate ranged from 53.0 to $54.3 \%$. This study used publicly available data and was exempt from institutional review board review.

Analytic Sample. After limiting the sample to adults $\geq 18$ years and excluding individuals with missing data on hospitalization $(<1 \%)$, our analytic sample included 55,186 respondents - representing more than 246 million Americans. To assess whether someone had been hospitalized in the previous year, we used the question: "Have you been hospitalized overnight in the past 12 months? Do not include an overnight stay in the emergency room."

Social Determinants of Health. We adopted and modified the Kaiser Family Foundation (KFF) model on Social Determinants of Health to classify specific NHIS questions into pre-defined domains of social risk. Briefly, the KFF model consists of six domains (economic stability, neighborhood and physical environment, education, food insecurity, community and social context, and health care access) that describe social elements that may adversely impact an individual's health. ${ }^{14}$ The NHIS questionnaires were assessed for questions that addressed each of the six domains. All questions were discussed among the authors and categorized into the most appropriate domain (Table 2). To maximize the sensitivity of our assessment, respondents were considered to have a SDOH if they answered positively to any question within each of the domains.

To assess the impact of SDOH burden on hospitalization, we created a social risk index that was composed of an individual-level count of $\mathrm{SDOH}$ domains, with categories including $0,1-2,3-4$, or $\geq 5$. Rates of missing among the unweighted data were $5.3 \%$ or less among the variables that were combined in each domain.

Covariates. To adjust for potential confounding, we included age, sex, ethnicity, race, health insurance status, and select health conditions in our analyses. These health conditions were obtained through the question, "Have you ever been told by a doctor or other health professional that you have [or take medications for]...?" with answers including hypertension, hyperlipidemia, coronary artery disease, myocardial infarction, stroke, asthma, peptic ulcer disease, cancer, prediabetes/diabetes, chronic obstructive pulmonary disease/emphysema/chronic bronchitis, kidney disease, liver disease/hepatitis, arthritis/rheumatologic disease, migraine, and chronic pain. Obesity was calculated using self-reported weight and height. A comorbidity count was summed per respondent with categories consisting of $0,1-2,3-4$, and $\geq 5$. Rates of missing among the unweighted data were less than $3.4 \%$ among the selected covariates.

Statistical Analysis. First, we calculated descriptive statistics to examine the association between the covariates, each $\mathrm{SDOH}$, and hospitalization status using Pearson's chi-square, and included estimated proportions and their $95 \%$ confidence intervals. Next, we estimated a set of multivariable logistical regression models for each SDOH while adjusting for age, sex, race, ethnicity, health insurance status, each comorbid condition, and all six $\mathrm{SDOH}$ domains. All descriptive and regression estimates accounted for the complex sampling design and sampling weights were used to produce estimates representative of the US population. Given the unknown and complex pathways between SDOH domains, we assessed for multicollinearity between all variables before modeling using Variance Inflation Factor 
(threshold: >10) and tolerance values (threshold: <0.1) and found no evidence of collinearity. Statistical analyses were performed using SAS statistical software version 9.4 (SAS Institute, Cary, NC).

\section{RESULTS}

Clinical Characteristics and Health Status. Among all 55,186 respondents, most were $\leq 50$ years old (54.2\%), female $(51.7 \%, 95 \%$ CI $51.1-52.3)$, non-Hispanic $(83.9 \%$, 95\% CI 82.4-84.5), identified as White $(77.9 \%, 95 \%$ CI 76.8-79.1), and had health insurance $(90 \%, 95 \%$ CI 88.9 91.9). The most commonly reported health conditions were hypertension $(31.5 \%, 95 \%$ CI 30.8-32.1), chronic pain (34.9\%, 95\% CI 34.2-35.7), obesity $(31 \%$, 95\% CI $30.3-$ $31.6)$, and hyperlipidemia $(28 \%, 95 \%$ CI $27.4-28.5)$, with most individuals reporting between 1-2 $(39.6 \%, 95 \% \mathrm{CI}$ $39.1-40.2)$ and $3-4(22.6 \%, 95 \% \mathrm{CI})$ comorbid diagnoses. Hospitalized individuals $(n=5506 ; 8.7 \%)$ were more likely to be $\geq 50$ years old $(61.2 \%)$, female $(60.7 \%$, 95\% CI 58.9-62.4), non-Hispanic (87\%, 95\% CI 86.2-88.4), and identify as White (78.5\%, 95\% CI 76.7-80.3), compared to those who were not hospitalized. Hospitalized individuals described poorer overall health, reporting higher incidence of having $\geq 5$ comorbid conditions $(38.9 \%, 95 \%$ CI 37.1-40.1) compared to those who did not report a hospitalization $(15.9 \%, 95 \%$ CI 15.4 16.5) (Table 1).

SDOH Prevalence. In the total cohort, nearly a quarter reported economic instability $(27 \%)$ or social isolation (24\%), almost two-thirds reported educational deficits (61\%), and close to one-in-ten reported a lack of community $(10 \%)$, or food insecurity (9\%). Almost one-insix reported substance use (16\%) or inadequate access to health care $(13 \%)$. Those who reported a hospitalization in the previous year had higher rates in six of the SDOH domains (economic instability [33\%], lack of community [14\%], educational deficits [67\%], food insecurity [14\%], social isolation [34\%]), and reported less access to health care $(6 \%)$ compared to non-hospitalized individuals.

Among those who reported economic instability, almost half stated they worry about maintaining current standard of living $(40.6 \%, 95 \%$ CI $38.8-42.5)$ or having enough money for retirement $(47 \%, 95 \%$ CI $45.3-48.8)$, while one-third worry about paying normal monthly bills $(33.2 \%, 95 \% \mathrm{CI}$ $31.5-34.9)$, and a quarter stated they worry about the inability to pay rent, mortgage, or housing costs $(25.5 \%, 95 \%$ CI 23.9 27.1). Among those who reported food insecurity, approximately one-in-five stated they either received food stamps or SNAP (Supplemental Nutritious Assistance Program) in the past year (18.0\%, 95\% CI 16.4-19.5), worried that food would run out $(18.9 \%, 95 \%$ CI 17.4-20.3), or that food would not last until they could buy more $(17.2 \%, 95 \%$ CI $15.7-18.7)$ (Table 2).

Association of SDOH with Hospitalization. In unadjusted analysis, increasing age, female gender, non-Hispanic ethnicity, Black race, and increasing comorbid burden were associated with hospitalization in the previous year. All assessed comorbid conditions were associated with hospitalization in univariate analysis. Among the six SDOH domains, five were associated with hospitalization with social isolation, food insecurity, and lower education attainment having the greatest impact.

Following adjustment for age, sex, ethnicity, race, health insurance status, and each individual comorbidity, older age ( $\geq 75$ years [OR: $1.24,95 \%$ CI 1.06-1.46]), female gender (OR: $1.42,95 \%$ CI 1.30-1.55), and multiple comorbid conditions (e.g., coronary artery disease, myocardial infarction, stroke, kidney disease) remained associated with hospitalization. Only three SDOH domains, food insecurity (OR: 1.36, 95\% CI 1.22-1.52), social isolation (OR: 1.17, 95\% CI 1.081.26), and lower educational attainment (OR: 1.12, 95\% CI $1.02-1.25)$, remained associated with hospitalization (Table 3).

SDOH Burden and Hospitalization. Among all respondents, few $(9.8 \%)$ reported no $\mathrm{SDOH}$, while $50.2 \%$ reported 1-2 $\mathrm{SDOH}, 34.4 \%$ reported $3-4$, and $5.6 \%$ reported $\geq 5 \mathrm{SDOH}$. In adjusted analysis, a higher $\mathrm{SDOH}$ burden was associated with increased odds of hospitalization (3-4 SDOH [OR: 1.25, 95\% CI 1.06-1.49] and $\geq 5$ SDOH [OR: $1.72,95 \%$ CI 1.40 2.06]) compared to those who reported no SDOH (Fig. 1).

\section{DISCUSSION}

In this national survey assessment of community-dwelling US adults, we found that three self-reported SDOH domains: low educational attainment, food insecurity, and social isolation were significantly associated with hospitalization. We also observed that as the cumulative number of individual-level SDOH increased, the risk of hospitalization also increased. These associations persisted after adjusting for a broad array of demographic and clinical variables known to be associated with hospitalization.

While the influence of SDOH on health and health outcomes is not new, these findings advance our understanding on the cumulative impact SDOH have on health care utilization. Previous work has highlighted the gradient or "doseresponse" of multiple adverse SDOH on clinical outcomes (e.g., control and management of diabetes). ${ }^{10,15}$ Additionally, there has been work exploring the association of SDOH on hospitalization. ${ }^{16,17}$ Yet, to our knowledge, little work has been done to capture the cumulative effect $\mathrm{SDOH}$ have on 
Table 1 Clinical Characteristics of Respondents to the National Interview Health Survey

\begin{tabular}{|c|c|c|c|c|}
\hline & \multicolumn{3}{|c|}{ Weighted \% (95\% confidence interval) } & \multirow[t]{2}{*}{$p$ value } \\
\hline & $\begin{array}{l}\text { Total cohort } \\
N=\mathbf{5 5 , 1 8 6}\end{array}$ & $\begin{array}{l}\text { No hospitalizations } \\
N=49,680\end{array}$ & $\begin{array}{l}\text { Hospitalization } \\
N=5506\end{array}$ & \\
\hline \multicolumn{4}{|l|}{ Age } & $<0.01$ \\
\hline $18-39$ & $38.1(37.3-38.9)$ & $39.1(38.3-39.9)$ & $28.0(26.3-29.6)$ & \\
\hline $40-49$ & $16.1(15.7-16.6)$ & $16.7(16.2-17.2)$ & $10.7(9.4-11.9)$ & \\
\hline $50-64$ & $25.3(24.8-25.9)$ & $25.4(24.8-26.0)$ & $24.9(23.4-26.4)$ & \\
\hline $65-74$ & $12.1(11.7-12.4)$ & $11.5(11.1-11.9)$ & $18.2(17.0-19.4)$ & \\
\hline$\geq 75$ & $8.2(7.8-8.5)$ & $7.2(6.9-7.5)$ & $18.1(16.8-19.4)$ & \\
\hline \multicolumn{4}{|l|}{ Sex } & $<0.01$ \\
\hline Female & $51.7(51.1-52.3)$ & $50.9(50.2-51.5)$ & $60.7(58.9-62.4)$ & \\
\hline \multicolumn{4}{|l|}{ Ethnicity } & $<0.01$ \\
\hline Hispanic & $16.1(14.7-17.3)$ & $16.3(15.0-17.6)$ & $13.0(11.2-14.8)$ & \\
\hline \multicolumn{4}{|l|}{ Race } & $<0.01$ \\
\hline White & $77.9(76.8-79.1)$ & $77.8(76.74-79.00)$ & $78.5(76.7-80.3)$ & \\
\hline Black & $12.3(11.4-13.2)$ & $12.1(11.24-12.97)$ & $14.6(13.0-16.2)$ & \\
\hline Asian & $6.2(5.7-6.8)$ & $6.5(6.01-7.08)$ & $3.5(2.7-4.3)$ & \\
\hline Other & $3.5(3.0-3.8)$ & $3.4(3.07-3.87)$ & $3.2(2.6-3.9)$ & \\
\hline \multicolumn{4}{|l|}{ Health insurance } & $<0.01$ \\
\hline None & $10.0(9.5-10.6)$ & $10.4(9.8-10.9)$ & $6.3(5.3-7.2)$ & \\
\hline \multicolumn{5}{|l|}{ Comorbid conditions } \\
\hline Hypertension & $31.5(30.8-32.1)$ & $29.4(28.8-30.1)$ & $52.6(50.9-54.3)$ & $<0.01$ \\
\hline Hyperlipidemia & $28.0(27.4-28.5)$ & $26.8(26.2-27.4)$ & $39.8(38.1-41.6)$ & $<0.01$ \\
\hline Coronary artery disease & $10.3(9.9-10.7)$ & $8.7(8.4-9.1)$ & $26.9(25.5-28.3)$ & $<0.01$ \\
\hline Myocardial infarction & $3.0(2.8-3.2)$ & $2.3(2.1-2.5)$ & $10.4(9.4-11.4)$ & $<0.01$ \\
\hline Stroke & $3.2(3.0-3.4)$ & $2.4(2.3-2.6)$ & $11.1(10.1-12.1)$ & $<0.01$ \\
\hline Asthma & $13.6(13.2-14.0)$ & $13.1(12.7-13.5)$ & $18.6(17.2-19.9)$ & $<0.01$ \\
\hline Peptic ulcer disease & $5.9(5.7-6.2)$ & $5.4(5.1-5.7)$ & $11.7(10.6-12.9)$ & $<0.01$ \\
\hline Cancer & $9.4(9.1-9.8)$ & $8.4(8.1-8.8)$ & $19.9(18.6-21.3)$ & $<0.01$ \\
\hline Diabetes/prediabetes & $12.7(12.3-13.1)$ & $11.5(11.2-11.9)$ & $24.4(22.7-26.1)$ & $<0.01$ \\
\hline COPD/emphysema/bronchitis & $6.3(6.0-6.6)$ & $5.4(5.1-5.7)$ & $15.5(14.3-16.7)$ & $<0.01$ \\
\hline Kidney disease & $2.2(2.0-2.3)$ & $1.6(1.5-1.8)$ & $8.2(7.4-9.1)$ & $<0.01$ \\
\hline Liver disease & $4.3(4.1-4.6)$ & $4.0(3.7-4.2)$ & $8.1(7.2-9.0)$ & $<0.01$ \\
\hline Arthritis/rheumatologic disease & $23.8(23.1-24.4)$ & $22.0(21.3-22.6)$ & $42.3(40.6-44.1)$ & $<0.01$ \\
\hline Migraine & $15.2(14.8-15.6)$ & $14.8(14.3-15.2)$ & $20.0(18.5-21.4)$ & $<0.01$ \\
\hline Chronic pain & $34.9(34.2-35.7)$ & $33.7(32.9-34.4)$ & $48.1(46.3-49.9)$ & $<0.01$ \\
\hline Obesity & $31.0(30.3-31.6)$ & $30.4(29.8-31.1)$ & $36.7(35.0-38.4)$ & $<0.01$ \\
\hline Mental health & $16.2(15.6-16.7)$ & $15.1(14.5-15.6)$ & $27.7(26.0-29.3)$ & $<0.01$ \\
\hline Substance use disorder & $12.1(9.9-16.5)$ & $13.3(10.1-14.9)$ & $14.0(8.9-16.1)$ & $<0.01$ \\
\hline \multicolumn{4}{|l|}{ Comorbidity count } & $<0.01$ \\
\hline 0 & $20.2(19.5-20.8)$ & $21.3(20.6-22.0)$ & $7.9(6.8-8.9)$ & \\
\hline $1-2$ & $38.6(38.1-39.2)$ & $40.0(39.4-40.6)$ & $24.3(22.7-25.8)$ & \\
\hline $3-4$ & $23.3(22.8-23.9)$ & $23.1(22.5-23.6)$ & $26.2(24.6-27.8)$ & \\
\hline$\geq 5$ & $17.9(17.3-18.4)$ & $15.6(15.0-16.1)$ & $41.7(39.9-43.4)$ & \\
\hline
\end{tabular}

COPD, chronic obstructive pulmonary disease. Substance use disorder includes heavy alcohol and tobacco use

hospitalization. This is likely due to the fact that assessing the impact of SDOH on a utilization outcome such as hospitalization is complicated - given that causal pathways are numerous, interconnected, and highly complex. For example, higher hospitalization rates may be driven by poor health literacy, but could be affected by food insecurity, lack of social connections, economic instability, and other interlinked social factors. Due to this complex interaction, efforts to quantify the impact of any single factor on a health outcome are likely inadequate, as they fail to capture the entire effect of an individual's social context. Our findings suggest that the clustering of SDOH may indicate a more substantial need to address these risk factors given the strong and wide influence $\mathrm{SDOH}$ have on a broad range of health conditions, clinical outcomes (e.g., cardiovascular disease, stroke, diabetes) ${ }^{3,9,11,18,19}$, and risk prediction models used by payors. ${ }^{3,4,20}$ We note that while these data indicate a small effect size, when applied to a national lens, even small, incremental increases in hospitalization risk could have substantial impact. In this case, our data indicate that four-in-ten American are at elevated risk of hospitalization due to their SDOH burden.

Our findings have important research and policy implications. First, this work highlights the importance of collecting, tracking, and utilizing SDOH to improve health and health outcomes. In 2014, the National Academy of Medicine (formerly known as the Institute of Medicine) recommended the routine collection of a panel of clinically significant SDOH measures that may be obtained by selfreport in advance of or during a health care encounter. ${ }^{21}$ Given the known complexity and interconnectedness of $\mathrm{SDOH}$, others have built upon this idea and proposed the development of an individualized "polysocial risk score" to identify at-risk individuals. ${ }^{22}$ Such a score could help predict the risk of varying combinations of social conditions and how they are related to specific health outcomes. Our results potentially support such an approach. 
Table 2 Prevalence of Social Determinants of Health Among a National Sample of Americans

\begin{tabular}{|c|c|c|c|c|}
\hline \multirow[t]{2}{*}{ Domains and specific questions of social risk } & \multirow{2}{*}{$\begin{array}{l}\text { Unweighted } \\
\text { frequency }\end{array}$} & \multicolumn{3}{|c|}{ Weighted \% (95\% confidence interval) } \\
\hline & & Total \% & $\begin{array}{l}\text { No } \\
\text { hospitalization }\end{array}$ & Hospitalization* \\
\hline \multicolumn{5}{|l|}{ Economic instability } \\
\hline Welfare assistance, job placement in the past year & 114 & $1.3(1.2-1.5)$ & $1.3(1.1-1.4)$ & $1.8(1.4-2.2)$ \\
\hline Cash assistance from state/county welfare & 99 & $1.2(1.1-1.3)$ & $1.1(1.0-1.3)$ & $1.9(1.4-2.4)$ \\
\hline Unemployed & 128 & $3.4(3.2-3.7)$ & $3.5(3.2-3.8)$ & $2.7(2.1-3.4)$ \\
\hline Ever applied for Social Security Income (SSI) & 642 & $4.7(4.4-5.0)$ & $4.2(3.9-4.5)$ & $10.2(9.0-11.3)$ \\
\hline Subsidized rent & 464 & $3.3(3.0-3.6)$ & $3.0(2.8-3.3)$ & $6.0(5.1-6.8)$ \\
\hline Worry about maintaining current standard of living & 2098 & $\begin{array}{l}36.2(35.5- \\
36.9)\end{array}$ & $35.8(35.0-36.5)$ & $40.6(38.8-42.5)$ \\
\hline Worry about enough money for retirement & 2395 & $\begin{array}{l}44.2(43.5- \\
44.9)\end{array}$ & $43.9(43.2-44.6)$ & $47.0(45.3-48.8)$ \\
\hline Worry about paying normal monthly bills & 1707 & $\begin{array}{l}26.7(26.0- \\
27.4)\end{array}$ & $26.1(25.3-26.8)$ & $33.2(31.5-34.9)$ \\
\hline Worry about inability to pay rent, mortgage, or housing costs & 1305 & $\begin{array}{l}21.2(20.5- \\
21.9)\end{array}$ & $20.8(20.1-21.5)$ & $25.5(23.9-27.1)$ \\
\hline Worry about making minimum payment on credit cards & 657 & $\begin{array}{l}11.8(11.3- \\
12.4)\end{array}$ & $11.7(11.1-12.2)$ & $13.4(12.2-14.6)$ \\
\hline \multicolumn{5}{|l|}{ Lack of community } \\
\hline People in your neighborhood do not help each other out & 441 & $6.7(6.4-7.1)$ & $6.5(6.2-6.9)$ & $8.5(7.5-9.4)$ \\
\hline There are no people you can count on in your neighborhood & 495 & $8.1(7.7-8.5)$ & $8.0(7.6-8.4)$ & $9.4(8.4-10.4)$ \\
\hline People in your neighborhood cannot be trusted & 448 & $6.8(6.4-7.2)$ & $6.6(6.2-6.9)$ & $9.2(8.0-10.3)$ \\
\hline Do not live in a close-knit neighborhood & 921 & $\begin{array}{l}14.8(14.2- \\
15.4)\end{array}$ & $14.5(13.9-15.1)$ & $17.5(16.1-19.0)$ \\
\hline \multicolumn{5}{|l|}{ Educational deficit } \\
\hline No college or graduate degree & 4085 & $\begin{array}{l}67.0(66.0- \\
68.0)\end{array}$ & $66.4(65.4-67.4)$ & $73.4(71.7-75.2)$ \\
\hline $\begin{array}{l}\text { Using your usual language, you have difficulty } \\
\text { communicating }\end{array}$ & 458 & $4.6(4.4-4.9)$ & $4.3(4.0-4.6)$ & $8.3(7.3-9.3)$ \\
\hline \multicolumn{5}{|l|}{ Food insecurity } \\
\hline Lose weight because not enough money for food & 271 & $1.9(1.7-2.1)$ & $1.7(1.5-1.9)$ & $4.2(3.5-4.9)$ \\
\hline Cut size of meals or skip meals in the past month & 582 & $5.4(5.1-5.7)$ & $4.9(4.6-5.2)$ & $10.0(8.9-11.1)$ \\
\hline Eat less than you should because not enough money for food & 612 & $5.6(5.3-5.9)$ & $5.2(4.8-5.5)$ & $10.1(9.0-11.2)$ \\
\hline Ever hungry but did not eat because no money for food & 410 & $3.4(3.2-3.6)$ & $3.0(2.8-3.3)$ & $7.0(6.1-7.9)$ \\
\hline Ever receive food stamps/SNAP in past year & 1021 & $\begin{array}{l}12.2(11.6- \\
12.8)\end{array}$ & $11.6(11.0-12.2)$ & $18.0(16.4-19.5)$ \\
\hline Worried that food would run out & 1056 & $\begin{array}{l}12.7(12.1- \\
13.2)\end{array}$ & $12.1(11.6-12.6)$ & $18.9(17.4-20.3)$ \\
\hline Food did not last until you could buy more & 961 & $\begin{array}{l}11.0(10.4 \\
11.5)\end{array}$ & $10.4(9.9-10.9)$ & $17.2(15.7-18.7)$ \\
\hline Did not eat balanced meals due to costs & 897 & $10.1(9.6-10.5)$ & $9.6(9.1-10.0)$ & $15.3(13.9-16.6)$ \\
\hline Received benefits or food subsidies from WIC program & 277 & $4.4(4.1-4.7)$ & $4.1(3.8-4.4)$ & $7.2(6.2-8.3)$ \\
\hline \multicolumn{5}{|l|}{ Social isolation } \\
\hline Lives alone & 3015 & $\begin{array}{l}41.0(40.3- \\
41.7)\end{array}$ & $40.8(40.1-41.6)$ & $42.2(40.4-44.1)$ \\
\hline Difficult to participate in social gatherings (clubs, parties) & 1118 & $6.0(5.7-6.3)$ & $4.7(4.4-4.9)$ & $19.8(18.2-21.4)$ \\
\hline Difficult to go shopping, movies, or sporting events & 1337 & $7.1(6.7-7.4)$ & $5.6(5.3-5.9)$ & $22.8(21.2-24.4)$ \\
\hline $\begin{array}{l}\text { Delayed getting medical care due to lack of transportation } \\
\text { Inadequate access to care }\end{array}$ & 308 & $1.9(1.7-2.1)$ & $1.7(1.5-1.8)$ & $4.7(3.9-5.5)$ \\
\hline Lacks regular place to go to when sick or need health advice & 297 & $\begin{array}{l}13.0(12.4- \\
13.6)\end{array}$ & $13.6(13.0-14.2)$ & $6.2(5.3-7.2)$ \\
\hline
\end{tabular}

*All questions were significantly different $(p<0.01)$ between the hospitalized and non-hospitalized group except for "lives alone" and "current tobacco use"

SNAP, Supplemental Nutrition Assistance Program; WIC, Women's, Infants, and Children's Nutritional Program

Second, our findings suggest that the clustering of social determinants of health may indicate a more substantial need to address these issues, especially given the strong and wide influence these factors have on a broad range of health conditions and outcomes. Given that $10 \%$ of American households are food insecure, ${ }^{23}$ that $22 \%$ of all American adults are socially isolated,$^{24}$ and that $30 \%$ of high-school graduates do not attend college, ${ }^{25}$ our findings amplify the need to address such issues.

We note that effective interventions to reduce social disparities will likely need to be multi-pronged and target individuals, providers, health care organizations, community and health care systems, and broader health policy. ${ }^{10}$ Importantly, there is an increasing number of health care systems and payers successfully investing in their local communities to address housing, food insecurity, and the built environment. ${ }^{26-30}$ For example, several practices have published evaluations of the effectiveness of hiring dedicated facilitators or patient navigators to assist socially isolated individuals, ${ }^{26}$ while the health insurance agency Anthem Blue Cross has implemented home delivered meal program for individuals who experience food insecurity. ${ }^{30}$ Yet, for any of these 
Table 3 Association of Clinical Characteristics and Social Determinants of Health on Hospitalization

\begin{tabular}{|c|c|c|}
\hline & $\begin{array}{l}\text { Unadjusted odds } \\
\text { ratio }(95 \% \text { CI) for } \\
\text { hospitalization }\end{array}$ & $\begin{array}{l}\text { Adjusted odds ratio } \\
\text { (95\% CI) for } \\
\text { hospitalization* }\end{array}$ \\
\hline \multicolumn{3}{|l|}{ Age } \\
\hline $18-39$ & Reference & Reference \\
\hline $40-49$ & $0.89(0.77-1.04)$ & $0.67(0.56-0.78)$ \\
\hline $50-64$ & $1.37(1.23-1.52)$ & $0.75(0.67-0.85)$ \\
\hline $65-74$ & $2.21(2.00-2.45)$ & $0.92(0.80-1.05)$ \\
\hline $75+$ & $3.49(3.13-3.89)$ & $1.24(1.06-1.46)$ \\
\hline \multicolumn{3}{|l|}{ Sex } \\
\hline Female & $1.49(1.38-1.61)$ & $1.42(1.30-1.55)$ \\
\hline Ethnicity & & \\
\hline Hispanic & $1.31(1.15-1.48)$ & $1.04(0.91-1.19)$ \\
\hline \multicolumn{3}{|l|}{ Race } \\
\hline White & Reference & Reference \\
\hline Black & $1.20(1.07-1.34)$ & $1.14(0.99-1.31)$ \\
\hline Asian & $0.54(0.44-0.67)$ & $0.77(0.61-0.97)$ \\
\hline Other & $0.93(0.77-1.13)$ & $0.91(0.73-1.14)$ \\
\hline \multicolumn{3}{|l|}{ Health insurance } \\
\hline None & $0.58(0.49-0.68)$ & $0.88(0.72-1.07)$ \\
\hline \multicolumn{3}{|l|}{ Comorbid conditions } \\
\hline Hypertension & $2.66(2.47-2.86)$ & $1.53(1.37-1.70)$ \\
\hline Hyperlipidemia & $1.81(1.67-1.95)$ & $0.90(0.81-1.00)$ \\
\hline $\begin{array}{l}\text { Coronary artery } \\
\text { disease }\end{array}$ & $3.84(3.55-4.16)$ & $1.86(1.68-2.06)$ \\
\hline $\begin{array}{l}\text { Myocardial } \\
\text { infarction }\end{array}$ & $4.84(4.28-5.46)$ & $1.66(1.41-1.95)$ \\
\hline Stroke & $4.97(4.40-5.60)$ & $1.97(1.69-2.29)$ \\
\hline Asthma & $1.51(1.37-1.66)$ & $1.05(0.93-1.17)$ \\
\hline Peptic ulcer disease & $2.33(2.06-2.63)$ & $1.25(1.08-1.45)$ \\
\hline Cancer & $2.70(2.45-2.97)$ & $1.63(1.46-1.82)$ \\
\hline Diabetes/prediabetes & $2.47(2.24-2.72)$ & $1.24(1.11-1.40)$ \\
\hline \multicolumn{3}{|l|}{ bronchitis } \\
\hline Kidney disease & $5.35(4.67-6.14)$ & $1.81(1.53-2.15)$ \\
\hline Liver disease & $2.12(1.87-2.40)$ & $1.25(1.06-1.46)$ \\
\hline $\begin{array}{l}\text { Arthritis/ } \\
\text { rheumatologic disease }\end{array}$ & $2.60(2.41-2.82)$ & $1.30(1.18-1.44)$ \\
\hline $\begin{array}{l}\text { Migraine } \\
\text {. }\end{array}$ & $1.44(1.31-1.59)$ & $1.03(0.91-1.16)$ \\
\hline Chronic pain & $1.83(1.69-1.97)$ & $1.10(1.00-1.21)$ \\
\hline Obesity & $1.33(1.23-1.44)$ & $1.00(0.91-1.09)$ \\
\hline Mental health & $2.16(1.97-2.36)$ & $1.50(1.35-1.68)$ \\
\hline $\begin{array}{l}\text { Substance use } \\
\text { disorder }\end{array}$ & $1.87(1.65-2.65)$ & $1.36(1.20-1.81)$ \\
\hline \multicolumn{3}{|l|}{ SDOH domains } \\
\hline Economic instability & $1.18(1.10-1.27)$ & $1.06(0.97-1.16)$ \\
\hline Lack of community & $1.24(1.13-1.36)$ & $1.03(0.92-1.15)$ \\
\hline Educational deficit & $1.46(1.34-1.59)$ & $1.12(1.02-1.25)$ \\
\hline Food insecurity & $1.68(1.54-1.82)$ & $1.36(1.22-1.52)$ \\
\hline Social isolation & $1.57(1.45-1.70)$ & $1.17(1.08-1.26)$ \\
\hline $\begin{array}{l}\text { Inadequate access to } \\
\text { medical care }\end{array}$ & $0.42(0.36-0.50)$ & $0.86(0.55-1.02)$ \\
\hline
\end{tabular}

*Adjusted for age, sex, race, ethnicity, health insurance status, comorbidities, and other SDOH domains. COPD, chronic obstructive pulmonary disease programs to be impactful, providers must first ask, document, and track potential social challenges so that such programs can be properly targeted.

Our assessment has several notable strengths. By using a national survey that asked granular, individual-level questions, this allowed us to explore both individual (income, education, food security) and identity factors (age, sex, race, ethnicity) - as well as a broad array of social, community, and neighborhood factors that other studies are frequently unable to obtain. ${ }^{11,31-33}$ Such granularity is important as studies have shown that more precise individual data can improve prediction modeling and offer a clearer understanding of the impact of SDOH on health. ${ }^{3,20}$ Additionally, while our domains are broad assessments of social risk based on a known SDOH framework, ${ }^{14}$ most domains are built from a large number of questions that can be easily ascertained in a clinical setting - thus increasing the applicability of these findings in a clinical environment. Of note, a recent implementation study of the NAM's recommended list of SDOH demonstrated that the collection of SDOH data is quick, taking approximately $5 \mathrm{~min}$, and that both patient and providers viewed the data collection as appropriate and important. ${ }^{34}$

\section{LIMITATIONS}

Our study also has notable limitations. First, although we examined six SDOH domains, our list is not a comprehensive exploration of all potentially impactful SDOH. Though, we note that our domains are constructed from 30 individual questions covering a broad range of topics in each domain, which allows us high sensitivity to detect the presence of any adverse SDOH. Second, some SDOH can be transient (e.g., food insecurity, housing situation) as individuals' social circumstances can change over time. However, other studies have shown that $\mathrm{SDOH}$, even when captured years prior, are still strongly associated with future outcomes. ${ }^{11,35}$ Third, while we controlled for a variety of sociodemographic and clinical factors associated with hospitalization, residual confounding could exist in our models. Fourth, our outcome of interests (hospitalization)

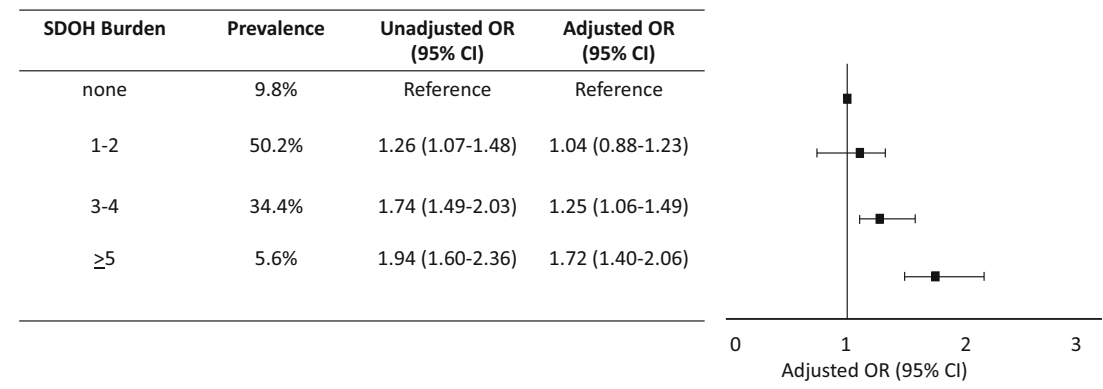

Figure 1 Forest Plot of the Association of SDOH Burden with Hospitalization. Adjusted for age, sex, race, ethnicity, health insurance status, and comorbid burden. 
is based off of self-report, which could be biased or incorrect, though prior work has shown that self-reported hospitalization is highly accurate. ${ }^{36}$ Fifth, the NHIS may not be a fully representative sample as it only gathers data in English and Spanish, does not involve individuals without a long-term address, and does not provide compensation for participation. These characteristics may present barriers to participation for households from disadvantaged communities, thus imparting some selection biases and skewing our findings. Finally, our assessment assumes equal weighting to all $\mathrm{SDOH}$ - assuming that all risk factors are interchangeable. This approach oversimplifies the complex causal social pathways that exist. However, there is currently no expert consensus on which $\mathrm{SDOH}$ confer a greater level of risk or whether a weighted model would outperform an unweighted model.

\section{CONCLUSIONS}

Among community-dwelling US adults, three common SDOH domains: food insecurity, social isolation, and low educational attainment appear to independently increase an individual's risk of hospitalization. Additionally, as an individual's SDOH burden (i.e., total number of SDOH) increases, so too does the risk of hospitalization. These findings expand upon a growing body of research that explores how $\mathrm{SDOH}$, as individual risk factors and in aggregate, impact health outcomes and health care resources. Moreover, these findings may support the importance of policy interventions focused on reducing social risk as a method to reduce hospitalization.

Acknowledgements: Charlie M. Wray had full access to all the data in the study and takes responsibility for the integrity of the data and the accuracy of the data analysis.

Corresponding Author: Charlie M. Wray, DO, MS; Section of Hospital Medicine, San Francisco Veterans Affairs Medical Center, San Francisco, USA (e-mail: Charlie.Wray@ucsf.edu).

Funding Dr. Wray is supported by a VA Health Services Research and Development Career Development Award (IK2HXOO3139-01A2).

\section{Declarations:}

Conflict of Interest: The authors declare that they do not have a conflict of interest.

Open Access This article is licensed under a Creative Commons Attribution 4.0 International License, which permits use, sharing, adaptation, distribution and reproduction in any medium or format, as long as you give appropriate credit to the original author(s) and the source, provide a link to the Creative Commons licence, and indicate if changes were made. The images or other third party material in this article are included in the article's Creative Commons licence, unless indicated otherwise in a credit line to the material. If material is not included in the article's Creative Commons licence and your intended use is not permitted by statutory regulation or exceeds the permitted use, you will need to obtain permission directly from the copyright holder. To view a copy of this licence, visit http://creativecommons. org/licenses/by/4.0/.

\section{REFERENCES}

1. Patient Trends in Hospital Inpatient Stays in the United States, 20052014 \#225. Accessed December 1, 2020. https://www.hcup-us.ahrq. gov/reports/statbriefs/sb225-Inpatient-US-Stays-Trends.jsp

2. Joynt KE, Jha AK. Thirty-Day Readmissions - Truth and Consequences. N Engl J Med. 2012;366(15):1366-1369. doi:https://doi.org/ 10.1056/NEJMp1201598

3. Maddox KEJ, Reidhead M, Hu J, et al. Adjusting for Social Risk Factors Impacts Performance and Penalties in the Hospital Readmissions Reduction Program. Health Serv Res. 2019;54(2):327-336. doi:https:// doi.org/10.1111/1475-6773.13133

4. Joynt Maddox KE, Chen LM, Zuckerman R, Epstein AM. Association Between Race, Neighborhood, and Medicaid Enrollment and Outcomes in Medicare Home Health Care. J Am Geriatr Soc. 2018;66(2):239-246. doi:https://doi.org/10.1111/jgs. 15082

5. Tsai TC, Orav EJ, Joynt KE. Disparities in Surgical 30-Day Readmission Rates for Medicare Beneficiaries by Race and Site of Care. Ann Surg. 2014;259(6):1086-1090. doi:https://doi.org/10.1097/SLA. 0000000000000326

6. Hu J, Gonsahn MD, Nerenz DR. Socioeconomic Status And Readmissions: Evidence from an Urban Teaching Hospital. Health Affairs. 2014;33(5):778-785. doi:https://doi.org/10.1377/hlthaff.2013. 0816

7. Joynt KE, Jha AK. Who Has Higher Readmission Rates for Heart Failure, and Why? Implications for Efforts to Improve Care Using Financial Incentives. Circ Cardiovasc Qual Outcomes. 2011;4(1):53-59. doi:https://doi.org/10.1161/CIRCOUTCOMES.110.950964

8. Rodriguez F, Joynt KE, López L, Saldaña F, Jha AK. Readmission Rates for Hispanic Medicare Beneficiaries with Heart Failure and Acute Myocardial Infarction. Am Heart J. 2011;162(2):254-261.e3. doi:https:// doi.org/10.1016/j.ahj.2011.05.009

9. Reshetnyak E, Ntamatungiro M, Pinheiro LC, et al. Impact of Multiple Social Determinants of Health on Incident Stroke. Stroke. 2020;51(8):2445-2453. doi:https://doi.org/10.1161/STROKEAHA.120. 028530

10. Echouffo-Tcheugui JB, Caleyachetty R, Muennig PA, Narayan KM, Golden SH. Cumulative Social Risk and Type 2 Diabetes in US Adults: the National Health and Nutrition Examination Survey (NHANES) 19992006. Eur J Prev Cardiol. 2016;23(12):1282-1288. doi:https://doi.org/ $10.1177 / 2047487315627036$

11. Sterling MR, Ringel JB, Pinheiro LC, et al. Social Determinants of Health and 90-Day Mortality After Hospitalization for Heart Failure in the REGARDS Study. J Am Heart Assoc. 2020;9(9). doi:https://doi.org/10. 1161/JAHA.119.014836

12. Leventhal AM, Bello MS, Galstyan E, Higgins ST, Barrington-Trimis JL. Association of Cumulative Socioeconomic and Health-Related Disadvantage With Disparities in Smoking Prevalence in the United States, 2008 to 2017. JAMA Intern Med. 2019;179(6):777-785. doi:https://doi. org/10.1001/jamainternmed.2019.0192

13. NHIS - National Health Interview Survey. Published November 3, 2020. Accessed December 1, 2020. https://www.cdc.gov/nchs/nhis/index. htm

14. Artiga S. May 10 EHP, 2018. Beyond Health Care: The Role of Social Determinants in Promoting Health and Health Equity. The Henry J. Kaiser Family Foundation. Published May 10, 2018. Accessed February 12, 2019. https://www.kff.org/disparities-policy/issue-brief/beyondhealth-care-the-role-of-social-determinants-in-promoting-health-andhealth-equity/

15. Kim EJ, Abrahams S, Marrast L, Martinez J, Hanchate AD, Conigliaro J. Significance of Multiple Adverse Social Determinants of Health on the Diagnosis, Control, and Management of Diabetes. J Gen Intern Med. Published online June 3, 2020. doi:https://doi.org/10.1007/s11606020-05860-9

16. Meddings $\mathbf{J}$, Reichert $\mathbf{H}$, Smith SN, et al. The Impact of Disability and Social Determinants of Health on Condition-Specific Readmissions beyond Medicare Risk Adjustments: a Cohort Study. J Gen Intern Med. 2017;32(1):71-80. doi:https://doi.org/10.1007/s11606-016-3869-x

17. Johnston KJ, Wen H, Schootman M, Joynt Maddox KE. Association of Patient Social, Cognitive, and Functional Risk Factors with Preventable Hospitalizations: Implications for Physician Value-Based Payment. J Gen Intern Med. 2019;34(8):1645-1652. doi:https://doi.org/10.1007/ s11606-019-05009-3

18. Walker RJ, Strom Williams J, Egede LE. Influence of Race, Ethnicity and Social Determinants of Health on Diabetes Outcomes. Am J Med Sci. 
2016;351(4):366-373. doi:https://doi.org/10.1016/j.amjms.2016.01. 008

19. Coughlin SS, Young L. Social Determinants of Myocardial Infarction Risk and Survival: A Systematic Review Eur J Cardiovasc Res. 2020;1(1). doi:https://doi.org/10.31487/j.ejcr.2020.01.02

20. Hammond G, Johnston $\mathbf{K}$, Huang $\mathbf{K}$, Joynt Maddox KE. Social Determinants of Health Improve Predictive Accuracy of Clinical Risk Models for Cardiovascular Hospitalization, Annual Cost, and Death. Circ Cardiovasc Qual Outcomes. 2020;13(6):e006752. doi:https://doi.org/10. 1161/CIRCOUTCOMES.120.006752

21. Committee on the Recommended Social and Behavioral Domains and Measures for Electronic Health Records, Board on Population Health and Public Health Practice, Institute of Medicine. Capturing Social and Behavioral Domains and Measures in Electronic Health Records: Phase 2. National Academies Press (US); 2015. Accessed July 1, 2020. http:// www.ncbi.nlm.nih.gov/books/NBK268995/

22. Figueroa JF, Frakt AB, Jha AK. Addressing Social Determinants of Health: Time for a Polysocial Risk Score. JAMA. 2020;323(16): 1553-1554. doi:https://doi.org/10.1001/jama.2020.2436

23. USDA ERS - Key Statistics \& Graphics. Accessed December 1, 2020. https://www.ers.usda.gov/topics/food-nutrition-assistance/food-security-in-the-us/key-statistics-graphics.aspx

24. DiJulio B, Muñana C. Loneliness and Social Isolation in the United States, the United Kingdom, and Japan: An International Survey Section 1: Characteristics and Experiences of Those Who Report Often Feeling Lonely or Socially Isolated. KFF. 2018 Published August 30, 2018. Accessed December 1, 2020. https://www.kff.org/report-section/loneliness-and-social-isolation-in-the-united-states-the-united-kingdom-andjapan-an-international-survey-section-1/

25. College Enrollment and Work Activity of Recent High School and College Graduates Summary. Accessed December 1, 2020. https://www.bls.gov/ news.release/hsgec.nro.htm

26. Andermann A. Taking Action on the Social Determinants of Health in Clinical Practice: a Framework for Health Professionals. CMAJ. 2016;188(17-18):E474-E483. doi:https://doi.org/10.1503/cmaj.160177

27. Social Determinants of Health: How Much Do We Understand? Accessed December 3, 2020. https://catalyst.nejm.org/doi/full/10.1056/CAT.16. 0751

28. Liburd LC, Jack L, Williams S, Tucker P. Intervening on the Social Determinants of Cardiovascular Disease and Diabetes. Am J Prev Med.
2005;29(5, Supplement 1):18-24. doi:https://doi.org/10.1016/j.amepre. 2005.07.013

29. Spectrum Health Expands Commitment to Address Health Inequities. Spectrum Health Newsroom. Published June 12, 2020. Accessed March 1, 2021. https://newsroom.spectrumhealth.org/spectrumhealth-expands-commitment-to-address-health-inequities/

30. Anthem Blue Cross Partners with Project Open Hand to Address Chronic Disease through Medically Tailored Meals. Anthem. Accessed March 1, 2021. https://www.anthem.com\#

31. Blosnich JR, Marsiglio MC, Dichter ME, et al. Impact of Social Determinants of Health on Medical Conditions Among Transgender Veterans. Am J Prev Med 2017;52(4):491-498. doi:https://doi.org/10. 1016/j.amepre.2016.12.019

32. Johnston KJ, Wen H, Schootman M, Joynt Maddox KE. Association of Patient Social, Cognitive, and Functional Risk Factors with Preventable Hospitalizations: Implications for Physician Value-Based Payment. J Gen Intern Med doi:https://doi.org/10.1007/s11606-019-05009-3

33. Hakulinen C, Pulkki-Råback L, Virtanen M, Jokela M, Kivimäki M, Elovainio M. Social Isolation and Loneliness as Risk Factors for Myocardial Infarction, Stroke and Mortality: UK Biobank Cohort Study of 479054 Men and Women. Heart. 2018;104(18):1536-1542. doi:https://doi.org/10.1136/heartjnl-2017-312663

34. Giuse NB, Koonce TY, Kusnoor SV, et al. Institute of Medicine Measures of Social and Behavioral Determinants of Health: a Feasibility Study. Am J Prev Med. 2017;52(2):199-206. doi:https://doi.org/10.1016/j.amepre. 2016.07.033

35. Gruenewald TL, Karlamangla AS, Hu P, et al. History of Socioeconomic Disadvantage and Allostatic Load in Later Life. Soc Sci Med. 2012;74(1):75-83. doi:https://doi.org/10.1016/j.socscimed.2011.09. 037

36. Bergmann MM, Byers T, Freedman DS, Mokdad A. Validity of Selfreported Diagnoses Leading to Hospitalization: a Comparison of Selfreports with Hospital Records in a Prospective Study of American Adults. Am J Epidemiol. 1998;147(10):969-977. doi:https://doi.org/10.1093/ oxfordjournals.aje.a009387

Publisher's Note: Springer Nature remains neutral with regard to jurisdictional claims in published maps and institutional affiliations. 